\title{
Application of remote sensing techniques for the identification of biotic stress in plum trees caused by the Plum pox virus
}

\author{
Dora Krezhova $^{1 *}$, Antoniy Stoev ${ }^{2}$, Nikolay Petrov ${ }^{2}$, Svetla Maneva ${ }^{2}$ \\ ${ }^{1}$ Space Research and Technology Institute \\ Bulgarian Academy of Sciences \\ Akad. G. Bonchev str., bl. 1, 1113 Sofia, Bulgaria \\ ${ }^{2}$ Institute of Soil Science, Agrotechnology and Plant Protection \\ Bulgarian Academy of Agriculture, \\ 35 Panayot Volov str., 2230 Kostinbrod, Bulgaria
}

\begin{abstract}
Two hyperspectral remote sensing techniques, spectral reflectance and chlorophyll fluorescence, were used for the identification of biotic stress (sharka disease) in plum trees at an early stage without visible symptoms on the leaves. The research was focused on cultivars that are widely spread in Bulgaria: 'Angelina', 'Black Diamond' and 'Mirabelle'. Hyperspectral reflectance and fluorescence data were collected by means of a portable multichannel fibre-optics spectrometer in the visible and near infrared spectral ranges $(400-1000 \mathrm{~nm})$. Statistical and deterministic analyses were applied for assessing the significance of the differences between the spectral data of healthy (control) and infected plum leaves. Comparative analyses were performed with complementary serological test DAS-ELISA, broadly implemented in plant virology. The strong relationship that was found between the results from the two remote sensing techniques and serological analysis indicates the applicability of hyperspectral reflectance and fluorescence techniques for conducting health condition assessments of vegetation easily and without damage before the appearance of visible symptoms.
\end{abstract}

Key words: chlorophyll fluorescence, DAS-ELISA, hyperspectral remote sensing, leaf reflectance, sharka

\section{INTRODUCTION}

Sharka (Plum pox virus) is considered to be one of the most devastating diseases of stone fruits in terms of agronomic impact and economic importance and is among the most studied viral diseases in the world (Dunez and Sutic 1988, Nemeth 1994). The disease was described for the first time around 1917 on plums and in 1933 on apricots in Bulgaria (Atanasoff 1932, 1935). Since then, the virus has progressively spread to a large part of the European continent, around the Mediterranean basin and the
Near and Middle East. It has also been found in India and in America (Chile, USA and Canada). Across Bulgaria the virus is most injurious to European plum (Prunus domestica). After the infection of trees, the yield can be completely compromised in cultivars of this crop that are sensitive to PPV (Atanasoff 1933, Trifonov 1972).

PPV is spread over long distances through the introduction of infected propagative plant material followed by local dispersion by aphids in a nonpersistent manner. Disease control is very difficult 
because sharka symptoms are highly dependent on both environmental conditions (temperature, age of the trees, etc.) and the sensitivity of the host plant. Symptoms of sharka may appear on leaves, petals, fruits and stones. They are particularly clear on leaves in the spring: mild light green discoloration, chlorotic spots, bands or rings, vein clearing or yellowing, or even leaf deformation. Flower symptoms can occur on petals (discoloration) of some peach varieties. In general, infected fruits show chlorotic spots or lightly pigmented yellow rings or line patterns. Fruits may become deformed or irregular in shape and develop small brown or necrotic areas. Diseased fruits may show internal browning of the flesh and reduced quality. In some cases the diseased fruits drop prematurely from the tree. In general early cultivars are much more sensitive to symptom expression on fruits than late cultivars (OEPP/EPPO 2004).

Depending on the the way and the source of the PPV infection, in many cases parts of the crown of the trees can remain uninfected or with a low virus concentration. For some varieties, leaf symptoms may not appear or may appear on separate leaves and not every year (Trifonov 1972, Vulić et al. 2011). The most common serological technique for the routine diagnosis of plant viruses is enzyme-linked immunosorbent assay (ELISA). With the aging of trees the number of branches with symptoms increases, but the spread of the disease does not remain the same. Therefore, in some cases ELISA results come out negative. On the other hand, some viruses cause asymptomatic infections, which at an early stage also give negative results and this facilitates their distribution. Negative results can be obtained due to inappropriate diagnostic reagents inconsistent with the strains of the pathogen specificity. Therefore, the application of different methods for the early diagnosis of diseases in plants and trees, based on different principles, is necessary.

Hyperspectral remote sensing (HRS) techniques are finding broadening applications and becoming increasingly valued as a useful tool for investigating the influence of environmental changes on vegetation. Their main benefits are rapid and more frequent data acquisition and faster and more automated processing over conventional field-based techniques. HRS techniques can be used for the assessment of the growth and health of horticultural crops, fruit quality, crop production forecasts, land monitoring and management, etc. (Pinter et al. 2003, Usha and Bhupinder 2013).
Their application for biotic stress detection helps in monitoring diseases in plants using the different plant spectral properties at the visible (VIS), near infrared (NIR) and shortwave infrared (SWIR) regions ranging from $350-2500 \mathrm{~nm}$ (West et al. 2003, Yang et al. 2009, Krezhova et al. 2012).

Terrestrial materials have different surface features (colour, structure and texture) and reflect or absorb electromagnetic radiation in different ways. The reflectance properties of objects depend on their particular material, and its physical and chemical state, and they have different colours and brightness. Thus, the objects can be differentiated by their spectral reflectance properties or spectral signatures, i.e. the measured reflected electromagnetic radiation at varying wavelengths in VIS (400-700 $\mathrm{nm})$, NIR (700-1200 $\mathrm{nm})$ and SWIR (1200-2500 nm) spectral ranges (Smith 2001). The combination of low VIS reflectance and high NIR reflectance is unique for vegetation types and it is changed in different way when plants are stressed or diseased (Campbell et al. 2007).

The HRS techniques based on reflectance and fluorescence data, which are acquired in a high number of contiguous spectral bands in VIS and NIR spectral ranges, have been successfully used to derive meaningful biophysical variables related to plant status (Bravo et al. 2003, Campbell et al. 2007). Moreover, the high spatial and spectral resolution of HRS technology increases the potential to detect anomalies in the normal plant growth and production processes at an early stage, before the damage has occurred (Krezhova 2011, Mahlein et al. 2012). In many cases, HRS remote sensing techniques have been used for preliminary identification of primary stress and diseases in plants and can replace the expensive, labour-intensive and time-consuming molecular techniques for plant disease detection.

In this study, two remote sensing techniques - spectral reflectance and chlorophyll fluorescence - were used for the identification of biotic stress caused by Plum pox virus (sharka disease) on plum trees at an early stage without visible symptoms on the leaves. The spectral responses of healthy and infected leaves from three cultivars - 'Angelina', 'Black Diamond' and 'Mirabelle', which are widespread in Bulgaria - in VIS and NIR spectral ranges were investigated. Comparative analyses were carried out using the accompanying serological test DAS-ELISA, one of the most widely used tests for plant viruses. 


\section{MATERIAL AND METHODS}

\section{Leaf material}

The plum trees were grown in three orchards near the Black Sea in the Burgas region. The trees in each orchard were from a different cultivar: 'Angelina', 'Black Diamond' and 'Mirabelle', widely distributed in Bulgaria. Up to 10 branches from the different parts of the top of the crowns of six plum trees from each of the investigated cultivars were subjected to analyses. Healthy leaves without visual symptoms of sharka and damages caused by aphids, acars or fungi (such as Polystigma rubrum, etc.) were collected in June 2014 from the branches. The leaves were with normal turgor and without signs of chlorosis. Leaf samples were stored in plastic bags and kept cool for the analysis. Leaf spectral measurements were conducted on randomly picked off leaves (50 from each cultivar) on the same day.

\section{Remote sensing methods}

\section{Spectral reflectance}

All green vegetation species have unique spectral features, mainly because of their chlorophyll (Chl) and carotenoids and other pigments, as well as their water content (Sims and Gamon 2002). The spectral signatures of green vegetation are quantified by spectral reflectance (SR), a property which is described by the dependence of the ratios of the intensity of reflected light to the illuminating light versus wavelength. The SR of healthy green vegetation has a significant minimum of reflectance in the VIS portion of the electromagnetic spectrum. Healthy plants exhibit low reflectance in both the blue and red regions owing to strong absorption by photoactive pigments (chlorophylls, anthocyanins, carotenoids) in plant leaves. Reflectance increases dramatically in the NIR region and depends on internal leaf tissue (cellular structure) and water content. Stressed vegetation can also be detected because it has a higher reflectance in the green and red spectral regions and significantly lower reflectance in the infrared region (Ustin and Gamon 2010, Krezhova et al. 2012). The shape of the reflectance spectrum can be used for the identification of vegetation type and plant health.

\section{Chlorophyll fluorescence}

Chlorophyll fluorescence (ChF) allows for the indirect study of the different functional levels of photosynthesis (e.g. process at the pigment level, primary light reaction, electron transport reaction, slow regulatory process) and can be used to study components of the photosynthetic apparatus and their reactions to changes in the environment (Maxwell and Johnson 2000, Schreiber 2004). Chl is the primary pigment of the plants that absorbs light energy from the Sun for photosynthesis. Excess energy can be dissipated as heat or re-emitted as light at a longer wavelength, i.e. chlorophyll fluorescence. Generally, $\mathrm{ChF}$ yield is highest when photochemistry and heat dissipation are lowest. Changes in $\mathrm{ChF}$ function take place before changes in Chl content, before any physical signs of tissue or chlorophyll deterioration are manifested in the plant, and therefore alterations in the fluorescence signal occur before any visible signs are apparent (Moshou et al. 2005, Bock et al. 2010).

$\mathrm{SR}$ and $\mathrm{ChF}$ are functions of optical tissue properties and the biological status of the plants, as well as the illumination conditions. In this respect, they have proved their potential by detecting stressrelated changes in the pattern of light emission from plant leaves (Usha and Bhupinder 2013).

\section{Spectral measurements}

Hyperspectral reflectance and fluorescence data were collected by means of a portable fibre-optics spectrometer (USB2000, Ocean Optics USA) in the VIS and NIR spectral ranges (450-850 $\mathrm{nm}$ and 600$850 \mathrm{~nm}$, respectively) under controlled illumination conditions. The light source for reflectance measurements is a halogen lamp providing homogeneous illumination of the leaf surface. For ChF measurements, an LED with maximum light output of $470 \mathrm{~nm}$ was used as a source of actinic light. SR analyses were performed in four regions that were most informative for the investigated species: green $(520-580 \mathrm{~nm}$, maximal reflectivity of green vegetation), red (640-680 nm, maximal chlorophyll absorption), red edge (680-720 $\mathrm{nm}$, maximal slope of the reflectance spectra) and NIR (720-770 nm). The spectral reflectance characteristics (SRC) of the investigated plants were determined as a ratio between the radiation reflected from the leaves and the radiation reflected from the diffuse reflectance standard. Specialized software was used for data acquisition and processing.

\section{Statistical analysis}

The Student's t-test was applied to determine the statistical significance of differences between the means of sets of values of the reflectance and fluorescence spectra of healthy (control) and infected leaves. Statistical analyses of the hyperspectral reflectance data were performed at the four above-mentioned spectral ranges in eight 
wavelengths $\left(\lambda_{1}=524.29 \mathrm{~nm}, \lambda_{2}=539.65 \mathrm{~nm}, \lambda_{3}\right.$ $=552.82 \mathrm{~nm}, \lambda_{4}=667.33 \mathrm{~nm}, \lambda_{5}=703.56 \mathrm{~nm}, \lambda_{6}$ $=719.31 \mathrm{~nm}, \lambda_{7}=724.31 \mathrm{~nm}$ and $\left.\lambda_{8}=758.39 \mathrm{~nm}\right)$, chosen to be disposed uniformly over these ranges. Statistical significance of the differences between fluorescence spectra of the control and infected leaves was analysed in five characteristic spectral bands, chosen at specific wavelengths: the middle of the forefront edge, first maximum, the middle between the first and second maximum, second maximum and the middle of the rear slope.

\section{Serological analyses}

\section{DAS-ELISA test (double antibody sandwich} enzyme-linked immunosorbent assay)

The analysis was conducted using the method of Clark and Adams (1977). We used a commercial kit from LOEWE Biochemica $\mathrm{GmbH}$, Sauerlach, Germany. ELISA plates were loaded with polyclonal antibodies (IgG) for Plum pox virus broad range (Cat. No. 07175), with dilutions (according to the instructions of the manufacturer) in $0.05 \mathrm{M}$ carbonate buffer. The samples were incubated for four hours at $37^{\circ} \mathrm{C}$, and the unbound components were washed out with PBS-T buffer for 5 min. All samples were grounded in an extraction buffer containing 1\% PVP (polyvinyl pyrrolidone) in a ratio of 1:10. The plates were incubated at $4^{\circ} \mathrm{C}$ for 16 hours. Following the third wash, step alkaline-phosphatase conjugate for PVY was added and the plates were incubated for four hours at $37^{\circ} \mathrm{C}$. The substrate used was p-nitrophenyl phosphate (p-nitrophenyl phosphate, Sigma) in a diethanolamine buffer ( $\mathrm{pH}$ 9.8) at a ratio of $1 \mathrm{mg} /$ $\mathrm{ml}$. The reaction proceeded in the light at room temperature and was stopped with $3 \mathrm{~N} \mathrm{NaOH}$. The absorbance of the colour reaction was measured using a multifunctional DTX 880 detector (Beckman, USA) at a wavelength of $405 \mathrm{~nm}$. The DAS-ELISA test was repeatedly done three times on the same samples. The positive samples had an average optical density (OD) over the threshold (cut-off $=0.462$ ), which was three times the value of the negative control.

\section{RESULTS AND DISCUSSION}

The averaged SRC (the mean SRC of all measured SRCs of one group of leaves, 25 for all the cases) of healthy plum leaves and and those infected with PPV of three cultivars - 'Angelina', 'Black Diamond' and 'Mirabelle' - are shown in Figures $1 \mathrm{a}), \mathrm{b})$ and c), respectively. The differences in SRC are expressed more significantly in the green, red and NIR spectral ranges.

The SRC values of the infected leaves increased in the green and red regions for all cultivars and for 'Mirabelle' the changes were most strongly expressed. The SRC values decreased in the NIR region except in the case of 'Mirabelle'. These differences appeared due to the changes that occurred in the physiological state of the plants (chlorophyll content, leaf cell structures, etc.) and water content. The statistical significance of the differences between the SRC of the control and that of the infected leaves are established by means of the Student's t-test. P-values and sets of means are shown in Table 1.

$\mathrm{R}_{\mathrm{i}} / \mathrm{R}_{\mathrm{ic}}(\mathrm{i}=1, \ldots, 8)$ designates that the sets of spectral reflectance data of the infected $\left(R_{i}\right)$ and control $\left(\mathrm{R}_{\mathrm{ic}}\right)$ leaves are compared at the $\mathrm{i}$-th wavelength $\left(\lambda_{1}=524.29 \mathrm{~nm}, \lambda_{2}=539.65 \mathrm{~nm}, \lambda_{3}=\right.$ $552.82 \mathrm{~nm}, \lambda_{4}=667.33 \mathrm{~nm}, \lambda_{5}=703.56 \mathrm{~nm}, \lambda_{6}=$ $719.31 \mathrm{~nm}, \lambda_{7}=724.31 \mathrm{~nm}$ and $\left.\lambda_{8}=758.39 \mathrm{~nm}\right)$.

Table 1. Means and p-values of the Student's t-test of SRC pairs of the control plum leaves and those infected with PPV for the cultivars 'Angelina', 'Black Diamond' and 'Mirabelle'

\begin{tabular}{lccccccccc}
\hline Virus infection & Control & \multicolumn{2}{c}{$\begin{array}{c}\text { PPV } \\
\text { Angelina }\end{array}$} & Control & \multicolumn{2}{c}{$\begin{array}{c}\text { PPV } \\
\text { Black Diamond }\end{array}$} & Control & \multicolumn{2}{c}{$\begin{array}{c}\text { PPV } \\
\text { Mirabelle }\end{array}$} \\
\hline Pairs compared & mean & $\mathrm{p}$ & mean & mean & $\mathrm{p}$ & mean & mean & $\mathrm{p}$ & mean \\
\hline $\mathrm{R}_{1} / \mathrm{R}_{1 \mathrm{c}}$ & 13.89 & $\mathrm{~ns}$ & 20.25 & 11.48 & $* *$ & 13.74 & 11.25 & $* * *$ & 14.32 \\
$\mathrm{R}_{2} / \mathrm{R}_{2 \mathrm{c}}$ & 16.37 & $* * *$ & 25.67 & 15.15 & $* *$ & 17.65 & 14.35 & $* * *$ & 18.42 \\
$\mathrm{R}_{3} / \mathrm{R}_{3 c}$ & 17.89 & $* * *$ & 27.30 & 15.99 & $* *$ & 18.96 & 15.09 & $* * *$ & 19.40 \\
$\mathrm{R}_{4} / \mathrm{R}_{4 c}$ & 5.40 & $\mathrm{~ns}$ & 9.52 & 4.77 & $\mathrm{~ns}$ & 6.34 & 6.02 & $\mathrm{~ns}$ & 6.30 \\
$\mathrm{R}_{5} / \mathrm{R}_{5 c}$ & 20.73 & $* * *$ & 30.55 & 17.36 & $* * *$ & 20.36 & 17.19 & $* * *$ & 21.61 \\
$\mathrm{R}_{6} / \mathrm{R}_{6 c}$ & 39.63 & $* *$ & 50.75 & 40.90 & $\mathrm{~ns}$ & 40.68 & 37.58 & $\mathrm{~ns}$ & 42.63 \\
$\mathrm{R}_{7} / \mathrm{R}_{7 \mathrm{c}}$ & 44.38 & $\mathrm{~ns}$ & 55.61 & 48.08 & $* * *$ & 46.77 & 43.64 & $*$ & 48.31 \\
$\mathrm{R}_{8} / \mathrm{R}_{8 c}$ & 55.42 & $\mathrm{~ns}$ & 66.28 & 67.46 & $* * *$ & 59.59 & 59.89 & $\mathrm{~ns}$ & 62.23 \\
\hline
\end{tabular}

Level of significance: $\mathrm{ns}-$ not significant, ${ }^{*} \mathrm{p}<0.05,{ }^{* *} \mathrm{p}<0.01, * * * \mathrm{p}<0.001$ 

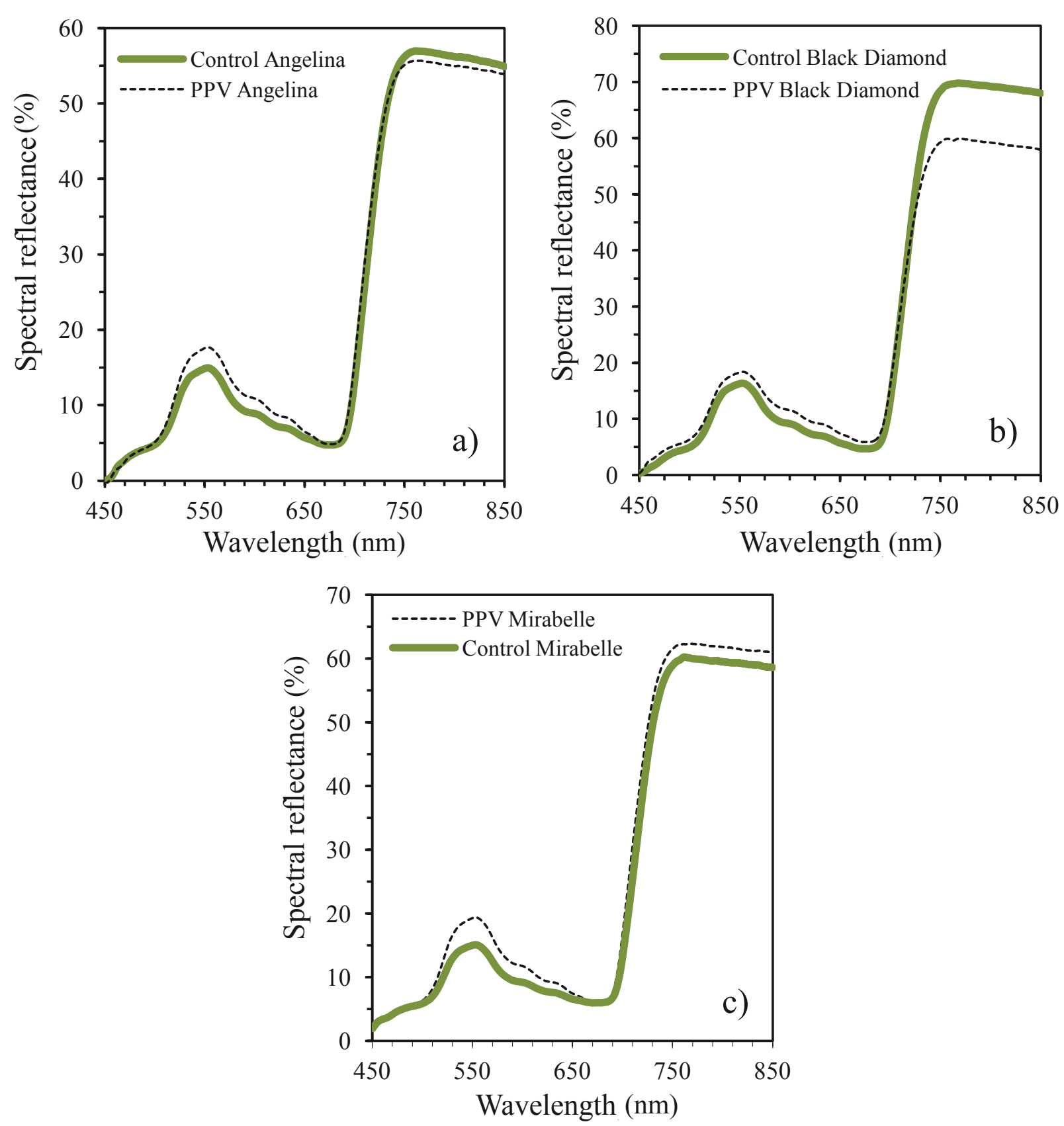

Figure 1. Averaged spectral reflectance characteristics of control and infected with PPV plum leaves, cultivars: a) Angelina, b) Black Diamond, c) Mirabelle

For all cultivars the differences are statistically significant in the green, red and NIR regions with the exception of the wavelength $\lambda_{4}$ (in the end of the red region). The number of statistically significant differences is the smallest (4) for the 'Angelina' cultivar and was increased for the other two cultivars. It is 6 for 'Black Diamond' and 5 for 'Mirabelle'. These results are an indicator of the presence of deviation from the normal status of the plum leaves.

The averaged fluorescence spectra of the 'Angelina', 'Black Diamond' and 'Mirabelle' plum cultivars are shown in Figure 2. They are normalised to the second maximum. The t-test was applied over the sets of data at five characteristic wavelengths located at the maximums of the spectra, the minimum between them, and at the middle of the forefront and rear slopes (650-800 $\mathrm{nm})$. The differences are statistically significant at the first three wavelengths for all of the cultivars and this confirms the results from spectral reflectance analyses for the presence of injury in the investigated leaves. 

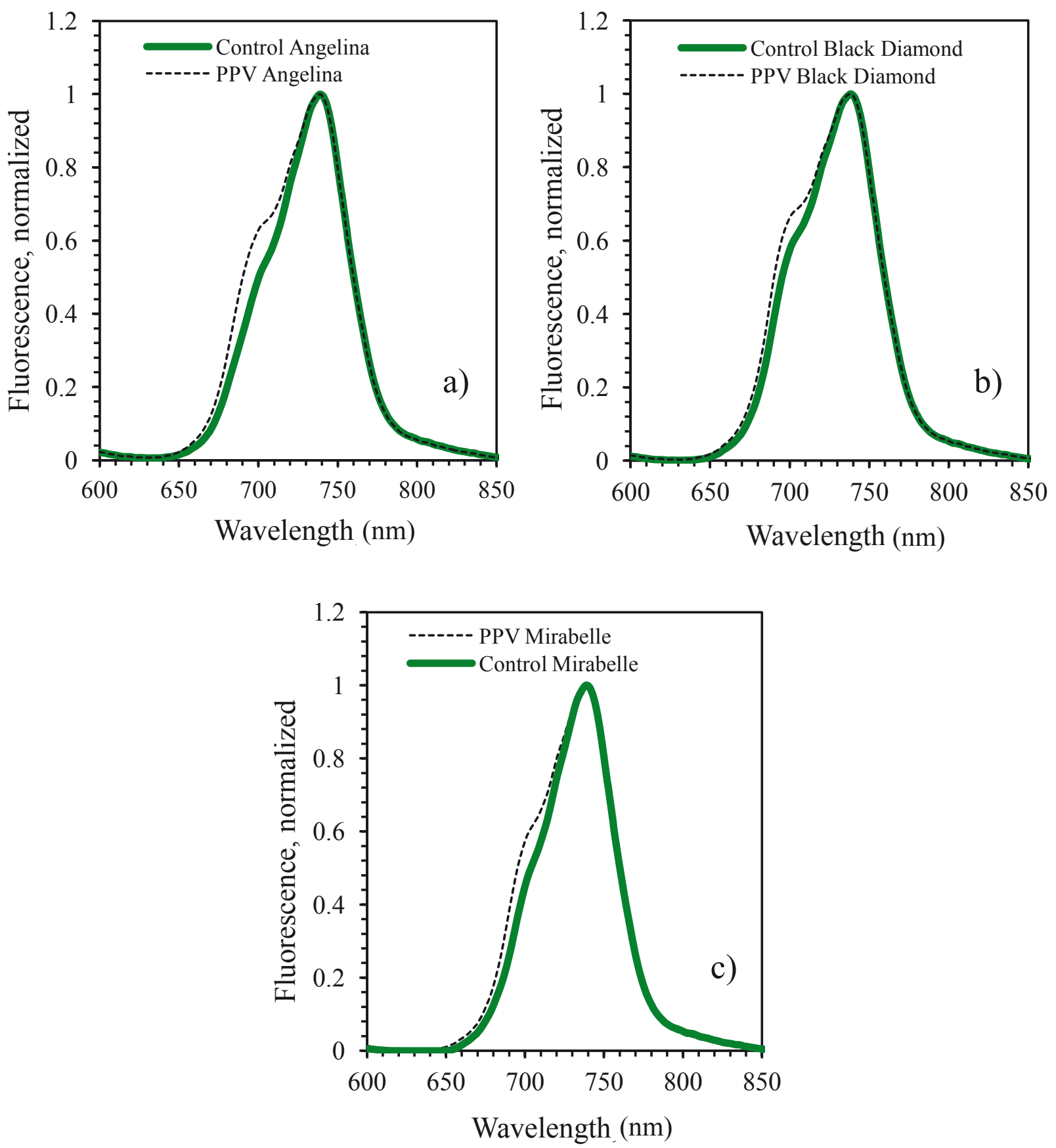

Figure 2. Averaged fluorescence spectra of control and infected with PPV plum leaves, cultivars: a) Angelina, b) Black Diamond, c) Mirabelle

The analyses by the DAS-ELISA test yielded a positive result for the presence of a viral infection in the infected leaves of the three plum cultivars. The DAS-ELISA values (average OD at a wavelength of $405 \mathrm{~nm}$ ) of the samples and standard deviations (Sd) are shown in Figure 3. All samples over the threshold (cut-off $=0.462$ ) are positive for PPV infection. The samples (1), (3) and (5) are negative for PPV infection and were used as the control groups for spectral measurements. The values of the OD for leaf samples from the cultivars 'Angelina' (2) and 'Mirabelle' (6) are approximately equal ( 0.8754 and 0.8613 , respectively). For leaf samples from 'Black Diamond' (4), the OD value is higher by a factor of 1.5 and the differences in NIR are more significant due to damages of the leaf tissue. The differences of SRC of samples (2) and (6) against the control SRC are similar in the VIS range. In the NIR region, the spectral behaviour is different for the three cultivars and indicates that leaf tissues (leaf cell structures) on the infected leaves of the cultivar 'Black Diamond' are the most damaged. 


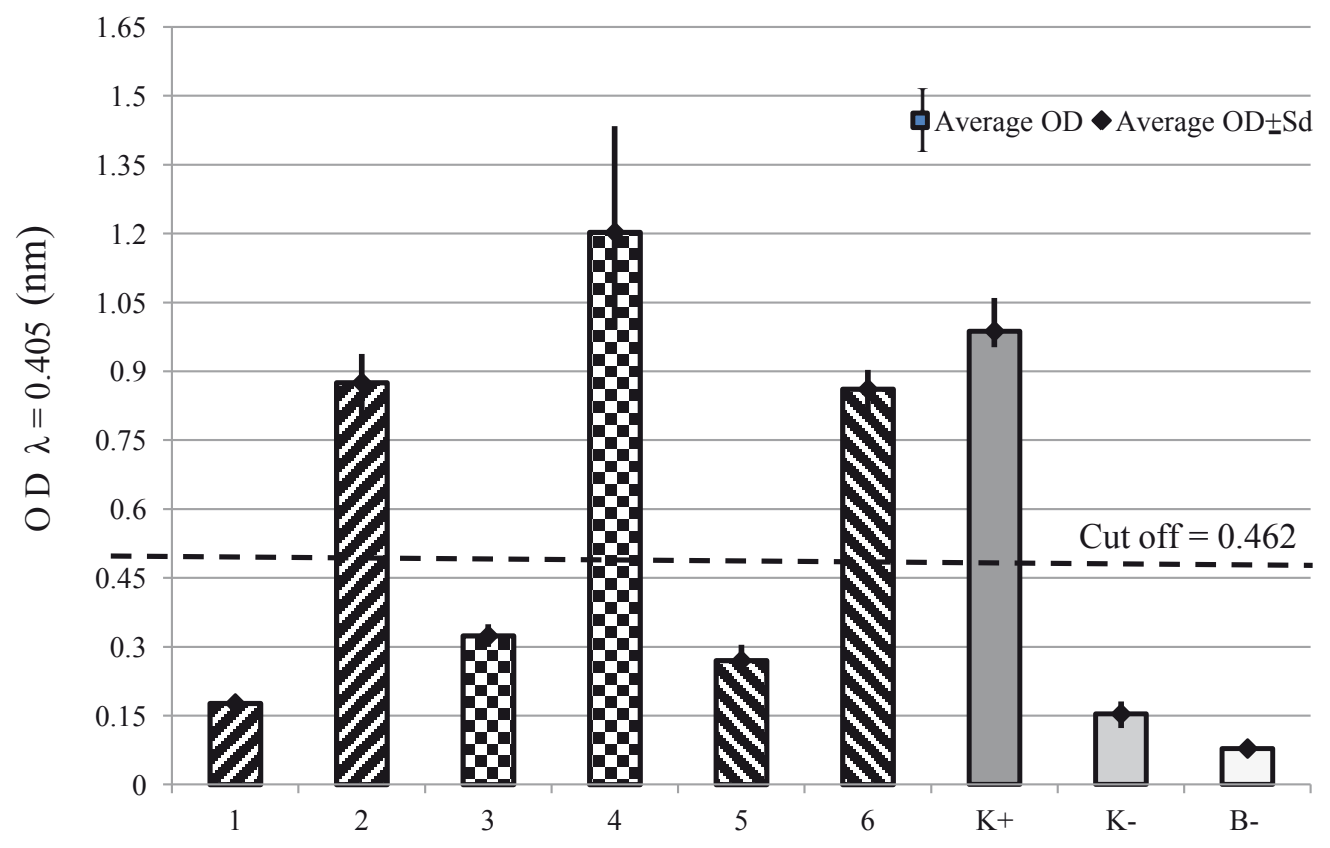

Figure 3. DAS-ELISA of plum samples for PPV infection

Legend: 1 - healthy plum 'Angelina', 2 - infected plum 'Angelina', 3 - healthy plum 'Black Diamond', 4 - infected plum 'Black Diamond', 5 - healthy plum 'Mirabelle', 6 - infected plum 'Mirabelle', K+ - positive control for PPV, $\mathrm{K}$ - -negative control for PPV, B- - negative control buffer, OD - optical density, Sd - standard deviation

\section{CONCLUSIONS}

1. The two applied remote sensing techniques revealed statistically significant differences between the spectral data of healthy plum leaves and those infected by PPV in the VIS and NIR spectral ranges.

2. The comparative analyses performed on the results from DAS-ELISA tests and the two remote sensing techniques revealed correlation between the extent of changes of the reflected and emitted radiation from plum leaves and the degree of the viral infection.

3. The strong relationship between the findings from the two hyperspectral techniques, leaf reflectance and chlorophyll fluorescence, indicates their applicability and effectiveness for preliminary screening for biotic stress (latent virus infection) in fruit trees and their importance for plant protection practices.

\section{REFERENCES}

Atanasoff D., 1932. Plum pox. A new virus disease. Yearb. Sof. Univ., Faculty of Agriculture and Silviculture 11: 49-69.

AtANASOFF D., 1933. Sharka - a new viral disease on plums in Bulgaria. Yearb. Sof. Univ., Faculty of Agronomy 11: 49-70.
Atanasoff D., 1935. Mosaic of stone fruits. Phytopathol. 8: 259-284.

Bock C.H., Poole G.H., Parker P.E., Gottwald T.R., 2010. Plant disease severity estimated visually by digital photography and image analysis, and by hyperspectral imaging. Crit. Rev. Plant Sci. 29: 59-107.

Bravo C., Moshou D., West J., McCartney A., Ramon H., 2003. Early disease detection in wheat fields using spectral reflectance. Biosys. Eng. 84(2): 137145.

Campbell P.K.E., Middleton E.M., Mcmurtrey J.E., Corp L.A., Chappelle E.W., 2007. Assessment of vegetation stress using reflectance or fluorescence measurements. J. Environ. Qual. 36: 832-845.

Clark M., Adams A., 1977. Characteristics of the microplate method of enzyme linked immunosorbent assay (ELISA) for the detection of plant viruses. J. Gen. Virol. 34: 475-483.

Dunez J., Sutic D., 1988. Plum pox virus. In: European Handbook of Plant Diseases. I.M. Smith, J. Dunez, R.A. Eliot, D.H. Phillips and S.A. Arches (eds), Blackwell, Oxford, UK: 44-46.

Krezhova D., 2011. Spectral remote sensing of the responses of soybean plants to environmental stresses, In: Soybean - Genetics and Novel Techniques for Yield Enhancement, Chapter 11. D. Krezhova (ed), Tech Publisher: 215-256.

Krezhova D.D., Petrov N.M., Maneva S.N., 2012. Hyperspectral remote sensing applications for monitoring and stress detection in cultural plants: 
viral infections in tobacco plants, Proc. of Remote Sensing for Agriculture, Ecosystems, and Hydrology Conf. September, Edinburgh, UK, XIV, 8531: 24-27.

Mahlein A-K., Oerke E.C., Steiner U., Dehne H-W., 2012. Hyperspectral imaging for small-scale analysis of symptoms caused by different sugar beet diseases. Plant Methods 8(3): 1-13. Available online at http:// www.plantmethods.com/content/8/1/3.

Maxwell K., Johnson G., 2000. Chlorophyll fluorescence - a practical guide. J. Exper. Botany, 51(345): 659-668.

Moshou D., Bravo C., Oberti R., West J., Bodria L., McCartney A., Ramon H., 2005. Plant disease detection based on data fusion of hyper-spectral and multi-spectral fluorescence imaging using Kohonen maps. J. Real-Time Image Processing 11(2): 75-83.

Nemeth M., 1994. History and importance of plum pox in stone-fruit production. Bulletin OEPP/EPPO Bulletin 24: 525-536.

OEPP/EPPO, 2004, Bulletin OEPP/EPPO Bulletin 34: 155-157.

Pinter P.J., Hatfield J.L., Schepers J.S., Barnes E.M., Moran M.S., Daughtry C.S.T., Upchurch D.R., 2003. Remote sensing for crop management. Photogramm. Eng. Remote Sens. 69: 647-664.

Schreiber U., 2004. Chlorophyll a Fluorescence: A Signature of Photosynthesis. G.C. Papageorgiou, and Govindjee (eds), Springer, Dordrecht, 279.

Sims D.A., Gamon J.A., 2002. Relationships between leaf pigment content and spectral reflectance across a wide range of species, leaf structures and developmental stages. Remote Sens. Environ. 81: 337-354.

Sмiтн R.B., 2001. Introduction to remote sensing of the environment. www.microimages.com

Trifonov D., 1972. Viral diseases on the fruit trees. Zemizdat, Sofia: 130-132.

Usha K., Bhupinder S., 2013. Potential applications of remote sensing in horticulture-A review. Sci. Horticul. 153: 71-83.

Ustin S.L., Gamon J,A., 2010. Remote sensing of plant functional types. New Phytol. 186: 795-816.

Vulić T., Nikolić D., Oparnica Č., ĐorĐević B., Kuzmanović S., Starović M., Đinović I., Nikolić N., Tosić M., 2011. Sectorial resistance of plums against sharka disease (Plum pox virus). Zastita bilja, Beograd, 62(1) 275: 5-15.

West J.S., Bravo C., Oberit R., Lemaire D., Moshou D., McCARtney H.A., 2003. The potential of optical canopy measurement for targeted control of field crop diseases. Annu. Rev. Phytopathol. 41: 593-614.

Yang Z., RaO M.N., Elliott N.C., Kindler S.D., Popham T.W., 2009. Differentiating stress induced by greenbugs and Russian wheat aphids in wheat using remote sensing. Comput. Electron. Agric. 67(1-2): 64-70.

Received January 30, 2015; accepted April 4, 2015 